\title{
Recent advances in shoulder research
}

\author{
Megan L Killian, Leonardo Cavinatto, Leesa M Galatz and Stavros Thomopoulos*
}

\begin{abstract}
Shoulder pathology is a growing concern for the aging population, athletes, and laborers. Shoulder osteoarthritis and rotator cuff disease represent the two most common disorders of the shoulder leading to pain, disability, and degeneration. While research in cartilage regeneration has not yet been translated clinically, the field of shoulder arthroplasty has advanced to the point that joint replacement is an excellent and viable option for a number of pathologic conditions in the shoulder. Rotator cuff disease has been a significant focus of research activity in recent years, as clinicians face the challenge of poor tendon healing and irreversible changes associated with rotator cuff arthropathy. Future treatment modalities involving biologics and tissue engineering hold further promise to improve outcomes for patients suffering from shoulder pathologies.
\end{abstract}

\section{Introduction}

As the elderly population expands, so do age-related orthopaedic disorders. This is of particular concern in the field of shoulder pathology, as both osteoarthritis (OA) and rotator cuff disease are degenerative conditions that increase in the aging population. These represent the most common causes of pain and disability, and have been subjects of research and treatment innovation in recent years. Arthritis of the shoulder can have a number of etiologies. Osteoarthritis, trauma, avascular necrosis, infection, and inflammatory arthropathies can all lead to loss of cartilage integrity and destruction of the joint surfaces. Loss of cartilage and incongruent joint surfaces result in painful articulation, necessitating orthopaedic treatment. Osteoarthritis is the most common cause of shoulder arthropathy and has been linked to age [1] and chronic overuse [2]. Conventional treatment options include nonsteroidal anti-inflammatory medication,

\footnotetext{
*Correspondence: Thomopoulos\$@wudosis.wustl.edu

Department of Orthopaedic Surgery, Washington University, St Louis, MO 63110, USA
}

cortisone injections, arthroscopic debridement, and joint replacement. It is expected that the rate of upper extremity arthroplasty will soon double and lead to increased health care costs and societal burdens [3].

Rotator cuff disease occurs in an age-related fashion and can exist along a spectrum, from rotator cuff tendinitis, to partial thickness rotator cuff tears, to full thickness rotator cuff tears. A recent study by Yamamoto and colleagues [4] demonstrated that the prevalence of cuff tears in a Japanese village was $20.7 \%$ for its general population; the risk factors identified for tears were history of trauma, arm dominance, and age. Others have shown that, in asymptomatic shoulders, an increased prevalence of tears is associated with increased age $[5,6]$. Tears can enlarge with time, and the increase in tear size is associated with retraction of the muscle tendon unit, which can lead to changes in muscle architecture [7], joint mal-alignment, and altered biomechanics [2]. Not all tears are symptomatic, although rotator cuff repair of painful tears is one of the most common orthopedic procedures in the US. In this review, we discuss the two major degenerative disorders of the shoulder, OA and rotator cuff disease, as well as new insights into how to treat these debilitating conditions.

\section{Shoulder pathology \\ Glenohumeral osteoarthritis \\ Etiology and pathology}

$\mathrm{OA}$, also known as degenerative joint disease, is defined as non-inflammatory degeneration of the cartilage and narrowing of the glenohumeral joint space. Radiographic findings of glenohumeral OA include joint space narrowing, circumferential osteophyte formation, subchondral cyst formation, posterior wear or bone loss of the glenoid, and/or subchondral sclerosis. Arthritis of the shoulder has many etiologies, including primary (idiopathic) and secondary (post-traumatic or developmental). Primary glenohumeral OA is considered rare [8], yet it is becoming an increasingly recognized source of pain and disability in the shoulder. Overuse and trauma have been correlated with increased risk of developing degenerative joint disease [9]. Increased intrinsic glenoid retroversion has been shown to lead to increased wear of the posterior glenoid, and these individuals are prone to earlier onset OA [10]. Chronic overuse of the shoulder can lead to 
excessive wear of the articulating surfaces with eventual thinning of the articular cartilage [11].

Post-capsulorraphy arthropathy is arthritis associated with surgical procedures for the treatment of instability, particularly from over-tightening of the anterior soft tissues of the shoulder. Over-tightening of the soft tissues leads to reduced external rotation and increased compressive load on the posterior articular cartilage of the glenoid, resulting in accelerated development of arthritis in the shoulder. Mal-positioned and migrated hardware, such as suture anchors or loosened screws, may also cause mechanical damage to the glenohumeral joint cartilage [12]. More recently, thermal injuries from soft tissue shrinkage devices used during shoulder arthroscopy have led to chondrolysis, and eventual OA [2].

The radiographic findings described above are in contrast to arthritis associated with inflammation (e.g., rheumatoid arthritis). Rheumatoid arthritis in the shoulder typically presents with medial wear of the glenoid, absence of osteophyte formation, large cyst formation, and osteopenia.

\section{Current treatment options for osteoarthritis}

The management of shoulder OA typically begins with nonoperative modalities before surgery is considered. The mainstays of non-operative treatment include oral and injected analgesics and anti-inflammatory drugs, physical therapy, and lifestyle modifications [13]. The goal of physiotherapy is to increase joint range of motion and strengthen muscles of the scapular girdle. Arthritic joints are prone to stiffness, and the stiffness is often a source of pain. Joint infiltration of local analgesics, often combined with steroidal anti-inflammatory drugs, is common and is often performed in out-patient settings. Steroid injections and visco-supplementation may provide short-term pain relief and help physicians diagnose intraarticular pathologies $[14,15]$. Such treatments are not without risk, however, and may lead to chronic degenerative changes to the joint and attenuation of the soft tissues in and around the joint [16].

When nonoperative treatment options no longer alleviate symptoms and symptoms interfere with daily activities and sleep, surgical management is often considered (Table 1). Treatment options include arthroscopic debridement, cartilage repair, and biological and arthroplastic replacement [17]. Arthroscopic debridement, with or without capsular release, may provide short-term relief of pain in the osteoarthritic shoulder; however, deterioration over time can be expected for most patients due to the loss of cartilage thickness and the inability to regenerate lost tissue. Some studies have demonstrated the benefit of this procedure as an early temporal bridge to arthroplasty $[18,19]$.
A major limitation to the consideration of an arthroplasty in a young patient is the longevity of the prosthesis. The rate of survival of a shoulder arthroplasty over the long term (15 to 20 years) is approximately $85 \%$ [20]. For young patients, alternatives are considered in order to avoid future revisions. Biologic resurfacing with a soft tissue interposition with or without humeral head replacement has led to controversial results [18,21-23]. Resurfacing with knee meniscus, Achilles allograft, anterior shoulder capsule, and other materials have all been reported. Early reports of biologic resurfacing were favorable, but recent mid-term results have indicated a high rate of failure and subsequent revision. Currently, glenoid resurfacing with biologic interposition is only recommended in young patients, in their third or fourth decade. Humeral head prosthetic resurfacing with stemless implants has also been considered in younger patients for humeral lesions [22]. The rationale is that a smaller resurfacing implant preserves proximal humeral bone stock, in the interest of future revision surgery. While this procedure has the potential advantage of minimal bone loss without humeral canal reaming, it is specific to treating small focal lesions or isolated humeral head arthrosis and may have little application in the setting of more severe OA [24-26].

Total shoulder arthroplasty (TSA) is the gold standard treatment for severe glenohumeral OA [27]. The growth rate for TSA continues to rise compared to other orthopedic joint replacement surgery rates [3]. Approximately 45,000 patients in the US undergo total shoulder arthroplasty or hemiarthroplasty each year [3]. A total shoulder arthroplasty involves replacement of the humeral head and prosthetic resurfacing of the glenoid (Figure 1). A hemiarthroplasty refers to humeral head replacement alone.

Total shoulder arthroplasty offers reliable pain relief, predictable improvement of function, and improved quality of life for a variety of shoulder arthropathies, including primary OA [28]. The main concern with TSA is the potential for loosening of the glenoid component over time, as this represents the most common complication [29,30]. Fixation [31] and material composition [32] are also factors related to the success of prostheses, as different materials and implantation methods may influence osteolysis and risk of arthroplasty revision. Recent results, however, support the longevity of polyethylene glenoid resurfacing [23]. Improvements in glenoid component materials and engineering are an ongoing subject of research.

Hemiarthroplasties are used mostly for select cases of arthritis, such as OA in a younger individual and rheumatoid arthritis in which bone loss precludes implantation of a glenoid component and rotator cuff arthropathy $[28,33]$. In general, hemiarthroplasty demonstrates 
Table 1. Procedures, advantages, and disadvantages for various surgical treatment modalities for severe osteoarthritis and rotator cuff disease

\begin{tabular}{|c|c|c|}
\hline Surgical procedure & Advantages & Disadvantages \\
\hline \multicolumn{3}{|l|}{ Osteoarthritis care } \\
\hline $\begin{array}{l}\text { Arthroscopic debridement } \pm \text { capsular release } \\
{[18,19]}\end{array}$ & $\begin{array}{l}\text { Low morbidity, low complication rate } \\
\text { Joint preserving } \\
\text { Simple rehabilitation }\end{array}$ & Less predictable outcome \\
\hline $\begin{array}{l}\text { Humeral head resurfacing with biologic } \\
\text { interposition [21-23] }\end{array}$ & $\begin{array}{l}\text { Avoids glenoid prosthesis } \\
\text { Obviates concerns over glenoid loosening over } \\
\text { time } \\
\text { Theoretically, preserves bone stock for future } \\
\text { reconstructive options }\end{array}$ & $\begin{array}{l}\text { Mixed results } \\
\text { Less predictable pain relief } \\
\text { Revision surgery in event of failure }\end{array}$ \\
\hline Hemiarthroplasty [28,33-36] & $\begin{array}{l}\text { Avoids glenoid prosthesis } \\
\text { Obviates concerns over glenoid loosening over } \\
\text { time } \\
\text { Shorter operation room time }\end{array}$ & $\begin{array}{l}\text { Less predictable pain relief } \\
\text { Increased time to maximal improvement } \\
\text { Lower survival rate } \\
\text { Risk of glenoid bone loss over time } \\
\text { Revision surgery in event of failure }\end{array}$ \\
\hline Total shoulder replacement $[19,35,36]$ & $\begin{array}{l}\text { Predictable pain relief } \\
\text { Predictable functional improvement } \\
\text { Proven longevity }\end{array}$ & Risk of glenoid loosening \\
\hline Cartilage repair or grafting techniques $[66,69,94]$ & $\begin{array}{l}\text { Joint preserving } \\
\text { Avoids or postpones arthroplasty procedure }\end{array}$ & $\begin{array}{l}\text { No long-term outcome result } \\
\text { Indicated in limited population, that is, young } \\
\text { individuals with isolated defects }\end{array}$ \\
\hline Rotator cuff disease care & & \\
\hline Rotator cuff repair [20,40-42,55,57,59] & $\begin{array}{l}\text { Favorable long-term outcome } \\
\text { Restores normal anatomy } \\
\text { Pain relief } \\
\text { Theoretically, protective against further } \\
\text { degenerative changes in muscle and tendon }\end{array}$ & $\begin{array}{l}\text { Long recovery } \\
\text { Tendon healing unpredictable }\end{array}$ \\
\hline $\begin{array}{l}\text { Debridement/biceps tenotomy/acromioplasty } \\
{[95,96]}\end{array}$ & $\begin{array}{l}\text { Indicated primarily for irreparable tear } \\
\text { Pain relief } \\
\text { Lower morbidity than muscle transfer or } \\
\text { arthroplasty }\end{array}$ & $\begin{array}{l}\text { Less predictable results } \\
\text { Further degenerative changes to bone and soft } \\
\text { tissue structures possible }\end{array}$ \\
\hline Muscle transfer [97] & $\begin{array}{l}\text { Salvage procedure for irreparable cuff } \\
\text { Potentially restores strength } \\
\text { Pain relief }\end{array}$ & $\begin{array}{l}\text { Limited indications } \\
\text { Mixed results } \\
\text { Long recovery period }\end{array}$ \\
\hline Reverse shoulder arthroplasty $[15,38,39]$ & $\begin{array}{l}\text { Salvage procedure for irreparable tear } \\
\text { Pain relief } \\
\text { Restores function }\end{array}$ & $\begin{array}{l}\text { Higher morbidity and complication rate } \\
\text { Limited indications, that is, older patients }\end{array}$ \\
\hline
\end{tabular}

inferior results when compared to TSA [27,34-36]; however, such procedures may be more appealing in certain settings, such as for very young patients, patients with severe bone loss, and patients with avascular necrosis involving only the humeral head [37].

A reverse shoulder arthroplasty is arguably one of the most important contributions to the treatment of certain shoulder arthropathies in the past several years. Reverse total shoulder arthroplasty is indicated primarily in the setting of rotator cuff insufficiency and rotator cuff arthropathy, but has also been used for fracture treatment, revision of failed shoulder arthroplasty, and sequelae of trauma. Reverse TSA prostheses have a ballin-socket design, with a semi-circumference ball being implanted in the glenoid and a stem with a concave polyethylene cap implanted in the humerus (Figure 1). Rotator cuff arthropathy represents a spectrum of shoulder pathology characterized by rotator cuff insufficiency, diminished acromiohumeral distance, and arthritic changes of the glenohumeral joint [38]. Reversal of the 


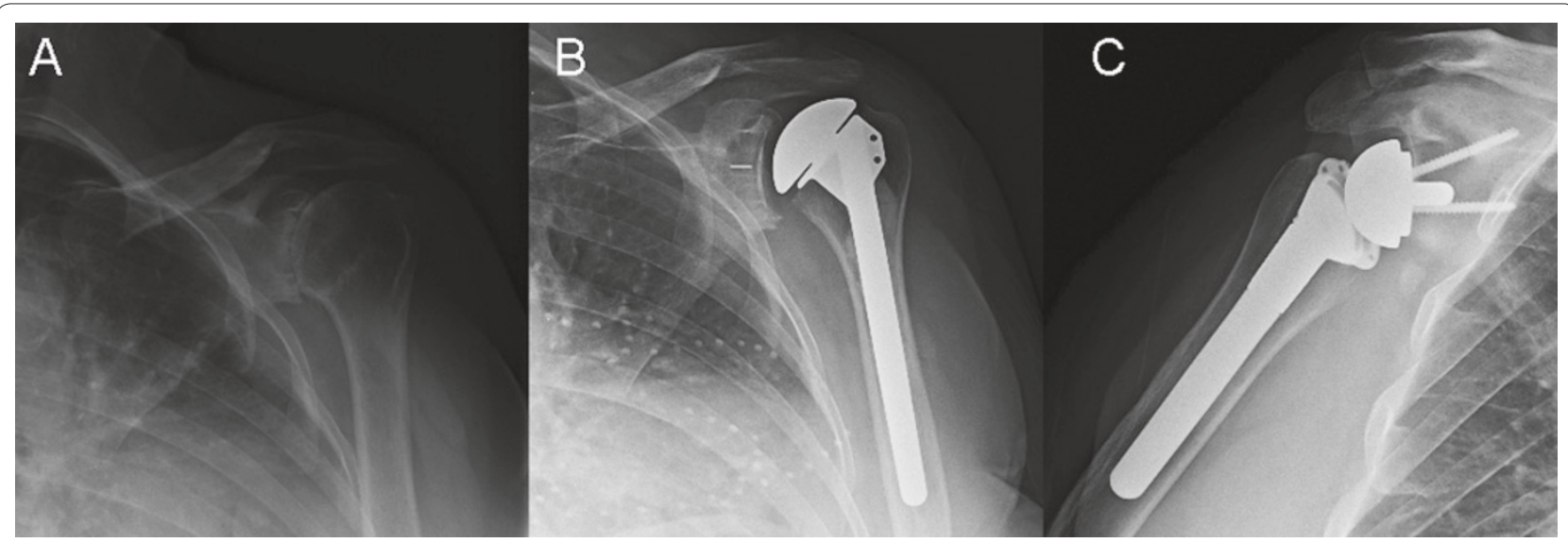

Figure 1. Total shoulder arthroplasty for treatment of severe glenohumeral osteoarthritis. (A) Pre-operative radiograph of an arthritic shoulder with typical loss of normal joint space. (B) Post-operative radiograph after total shoulder replacement of both humeral head and glenoid components. (C) Post-operative radiograph of a shoulder with a reverse shoulder arthroplasty for rotator cuff arthropathy.

components changes the biomechanics of the construct, allowing overhead elevation in the absence of a rotator cuff. A competent deltoid is critical for a successful reverse shoulder arthroplasty, as this becomes the primary actuator of the shoulder. Recently, some surgeons have expanded the use of this prosthesis to treat other shoulder conditions, such as irreparable rotator cuff tears without glenohumeral arthritis and rheumatoid arthritis; preliminary studies have had favorable short-term results $[28,39]$.

\section{Rotator cuff disease \\ Etiology and pathology}

Rupture of one or more of the rotator cuff tendons from the humeral head is one of the most common orthopedic injuries in the US, with over 250,000 repairs performed each year [3]. Large rotator cuff tears, which include more than one of the rotator cuff tendons, lead to increased morbidity and probability of post-surgical repair-site failure [40]. Additionally, many factors may perpetuate the likelihood of a failed repair, including age, gender, severity and duration of injury [41,42]. Regardless, the predictability of failure and the factors associated with impaired healing and reduced strength of the repaired rotator cuff are currently unclear. In both the clinic and in animal models, changes in muscle architecture and structure have been associated with chronic rotator cuff disease $[7,43,44]$, and a role for rotator cuff muscle health and rehabilitation in healing repairs has been suggested $[45,46]$. Following a rotator cuff tear, fatty accumulation [47] and atrophy [44] are thought to play a role in the reparability of the tendon-to-bone insertion, as these factors can lead to increased repair site tension due to tenomuscular retraction and muscle fibrosis [48]. Recent animal studies have elucidated the pathomechanisms of fatty degeneration of the rotator cuff muscles after chronic cuff tears [49-51]. Rotator cuff tears in rodents led to accumulation of adipocytes, intramuscular fat globules, and intramyocellular fat droplets in the injured muscles (Figure 2). Adipogenic and myogenic transcription factors and markers were upregulated in the injured rotator cuff muscles, and the severity of changes was associated with tear size and concomitant nerve injury. The status of the rotator cuff by serial ultrasound examination after large and massive rotator cuff repairs has been used to potentially delineate failure mechanisms as having either mechanical or biological causes. High tension at the repair site immediately post-surgery may increase the risk for mechanical failure of the repair site [48]. Failure of the repair site may also result from a lack of appropriate healing at the tendon-to-bone insertion [52]. Improvements in both tendon-to-bone insertion strength as well as promotion of tendon-to-bone healing are precedent in order to advance the success of rotator cuff repair strategies.

\section{Current treatment options for rotator cuff disease}

Treatment modalities for rotator cuff disease are dependent on the severity of degeneration and symptoms of the patient; various surgical treatment options are outlined in Table 1. While acute, traumatic rotator cuff tears can be treated surgically with high success rates and marginal morbidity, treatment of chronic rotator cuff disease is less promising. Surgical repairs of chronic rotator cuff tears are less likely to heal than acute repairs, and 30 to $94 \%$ of arthroscopic repairs of large, chronic rotator cuff injuries have the potential to fail, particularly within the first 2 years $[40,53]$. Even with current repair techniques, including arthroscopic double-row repairs, failure rates post-repair remain high $[54,55]$, suggesting 

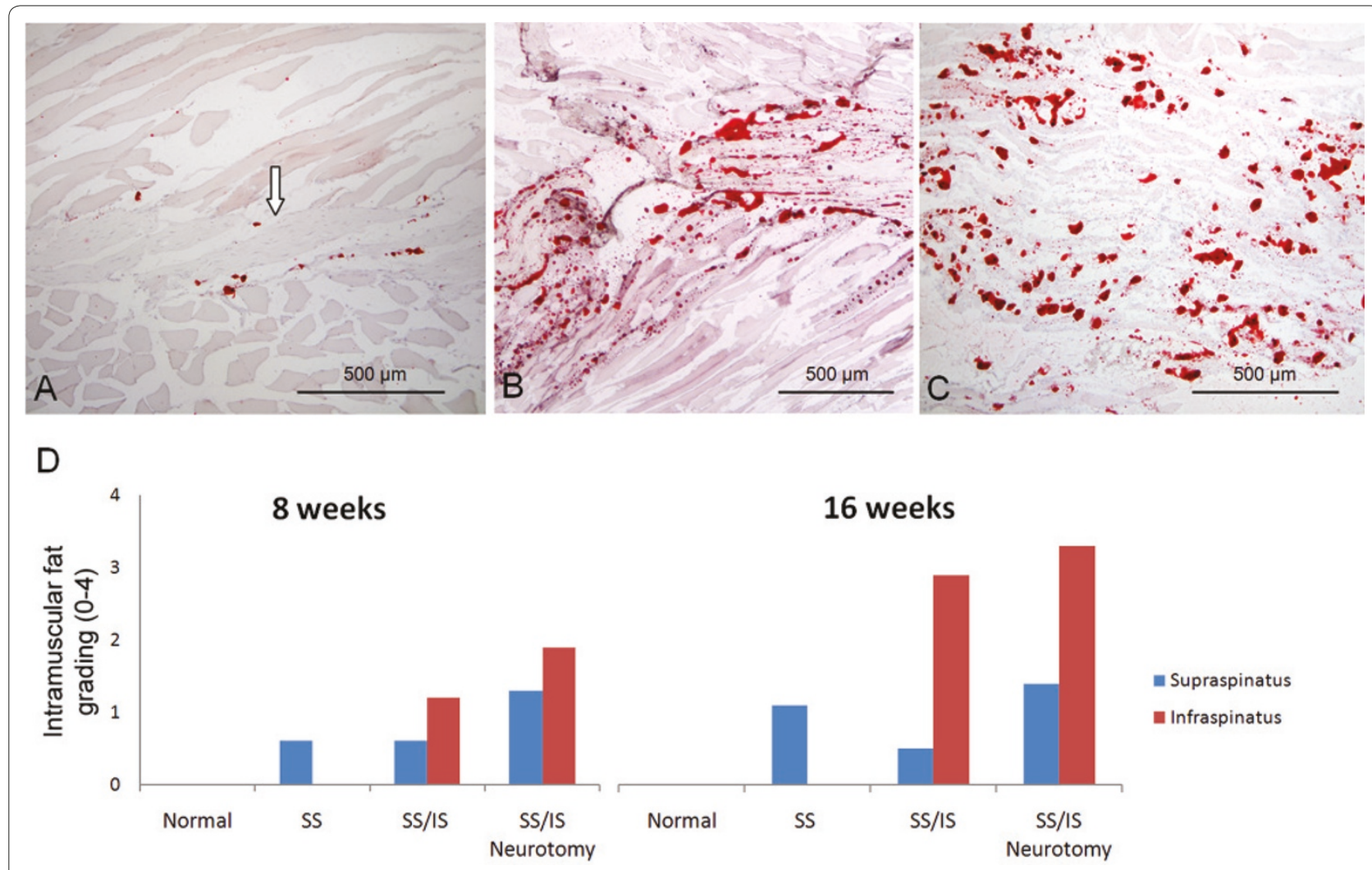

Figure 2. Fatty accumulation in a rodent model of chronic rotator cuff degeneration. (A) A normal rat supraspinatus muscle stained with Oil red $\mathrm{O}$ showing very few intramuscular fat deposits and intramyocellular fat droplets. The supraspinatus tendon can be seen at the center of the muscle (arrow) and the muscle fibers can be seen above and below the tendon. (B) The infraspinatus muscle of a rat 16 weeks following tenotomy of the supraspinatus and infraspinatus tendons. There are high numbers of fat deposits (seen as red dots). (C) The infraspinatus muscle of a rat 16 weeks following tenotomy plus neurotomy showing high levels of intramuscular fat. (A-C) Oil red O stain; 10x objective. (D) Histology grading results are shown for intramuscular fat on Oil red O stained histology sections. Normal muscles showed no fat. After tenotomy of the supraspinatus (SS) and infraspinatus (IS) tendons, the infraspinatus muscle had more intramuscular fat than the supraspinatus muscle. The 16-week specimens had more intramuscular fat than the 8-week specimens within each group. Note that grading was semi-quantitative in nature; statistical comparison and error bars were therefore not calculated. Reproduced with permission from [50].

the potential role of aging and degeneration in recurring tendon-to-bone failure [56-59]. The healing tendon-tobone insertion following rotator cuff repair is dissimilar to the native insertion, which demonstrates four distinct transitional zones: bone, calcified fibrocartilage, uncalcified fibrocartilage, and tendon. Instead, the healing tendon forms a fibrovascular scar tissue and is biomechanically weaker and more prone to failure than the native insertion [60].

Even though patients symptomatically improve after surgically repaired rotator cuff tears regardless of the structural status of the cuff in the postoperative period, studies suggest a better clinical outcome when the repair remains intact and the cuff heals back on the greater tuberosity [40,61]. Moreover, some investigations show that increased age, larger tear size, poorer muscle quality, delamination of the tendons, and longer follow-up are all related to lower healing rates and inferior clinical results $[41,42]$. Miller and colleagues [62] recently investigated the potential mechanisms of failed repairs by verifying the chronological status of the rotator cuff using serial ultrasound examination after rotator cuff repairs. The great majority of the recurrent tears (seven of nine) occurred very early in the postoperative period, perhaps suggesting a mechanical cause for the failure. Nevertheless, it remains unclear whether mechanical or biological reasons are responsible for impaired cuff healing and failure. Efforts have been made in order to improve the initial fixation strength and to better recreate the normal anatomical footprint of the rotator cuff. The use of the double-row technique, or the addition of another row of suture anchors to the fixation construct to improve structural function and re-establish the rotator cuff footprint, has been implemented in recent years [42]. While these techniques may lead to higher healing rates, multiple clinical studies have not shown a translation from improved insertion strength to better functional or clinical outcomes $[63,64]$. It is likely that, even with the 
mechanical strength of the repair maximized, high failure rates are still prone to occur. Thus, exploring the underlying biological environment, while optimizing the present mechanical constructs, may drive the future success of rotator cuff repair.

\section{Future therapies and treatment modalities}

The development of therapies to improve the healing rate and functional outcomes after the onset of $\mathrm{OA}$ and rotator cuff damage is currently driven by several factors, including functional improvements in the strength of the repair, targeted biochemical signaling of the repair site to encourage the healing process, and establishment of native cartilage and/or tendon-to-bone insertion. Tissue engineering may provide avenues for encouraging growth, healing, and remodeling of injured musculoskeletal tissues, particularly of articular cartilage lining the glenohumeral joint and the tendon-to-bone insertion of the rotator cuff (Figure 3).

\section{Osteoarthritis}

\section{Scaffolds and grafts}

While surgery remains the last resort option for treatment of severe shoulder degeneration, compelling reasons exist to prolong the need for arthroplasty solutions, especially in younger patients. Bioengineered devices, such as tissue engineered grafts, are currently being developed and may play a substantial role in the healing and structural maintenance of glenohumeral articular cartilage $[23,65,66]$. Most approaches incorporate one or more components of the tissue engineering paradigm described in Figure 3. Recently, Gobezie and colleagues [66] implemented an all-arthroscopic total shoulder cartilage resurfacing technique for treatment of advanced glenohumeral OA in young patients. Using osteoarticular allografts from cadaveric tibial plateaus and humeri, bipolar cartilage resurfacing demonstrated early success and rehabilitation [66]. Similarly, Krishnan and colleagues [23] performed successful glenoid resurfacing with fascia lata autograft in some patients and Achilles tendon allograft in others. In this study, the use of allogenic resurfacing material showed promise for reducing postoperative pain as well as for excluding donor site morbidity that is observed when using autografts [23]. Glenoid resurfacing has proven successful after 3 to 6 years following implementation of a xenograft patch seeded with pluripotent cells [65]. However, due to progressive glenohumeral space narrowing, the durability of biologic soft tissue interposition grafts may present a long-term concern [21]. Additionally, disease transmission and host rejection are potential issues when implementing biologically derived materials from allogenic or xenogenic sources. Nonetheless, chondrocyte and osteochondral plugs and articular grafts from autogenic or allogenic sources have successfully demonstrated their potential as biologic alternatives to debridement for the treatment of cartilage defects [13,67-69], and more research is needed to better interpret their efficacy.

\section{Rotator cuff repair \\ Scaffolds and grafts}

A number of scaffolds have been used clinically in an effort to augment rotator cuff tendon-to-bone repair. However, a review of currently available scaffolds by Derwin and colleagues revealed that further work is necessary to optimize scaffold properties [70]. Clinically available scaffolds lack an appropriate recreation of the native tissue's gradation in properties between the compliant tendon and the stiff bone. To address this lack of complexity, laboratory tissue engineering work has focused on a number of approaches. Biphasic [71] and triphasic scaffolds [72] have been generated and seeded with multiple cell types. These studies demonstrated the importance of signaling between the various tendon-tobone cell types for generation of a functional insertion. More recent approaches have also attempted to create continuous gradients in composition and properties in order to recreate the interface that is seen at the natural rotator cuff tendon-to-bone insertion. To this end, electrospun polymer nanofiber scaffolds were synthesized with gradations in mineral, mimicking the mineral gradation seen at the native insertion [73]. The gradation in mineral content resulted in a spatial variation in the stiffness of the scaffold. Similar results were reported using a cell-seeded collagen scaffold with a gradient in retrovirus encoding an osteogenic transcription factor [74]. A tissue engineered scaffold with a gradation in properties and seeded with the appropriate cells and biofactors may ultimately provide a solution to the clinical problem of tendon-to-bone healing.

\section{Biological aids}

Throughout soft tissue healing, several growth factors and catabolic molecules have been shown to regulate scar formation and remodeling [75]. Such alterations in biomarker production can provide insight into the normal biological response of the healing tendon, cartilage, and bone. The use and/or combination of exogenous growth factors, stem cells, and bioengineered scaffolds may demonstrate potential in encouraging healing and repair of the rotator cuff [76-80]. The use of individual molecules, such as bone morphogenetic protein-2 (BMP-2) and transforming growth factor (TGF)- $\beta 3$, to aid cartilage and tendon-to-bone healing has been explored [78-85], yet it is likely more beneficial to incorporate a cocktail of growth factors to best promote healing, of which the constituents are currently unknown [78]. Regardless, harmonious signaling initiated by both 


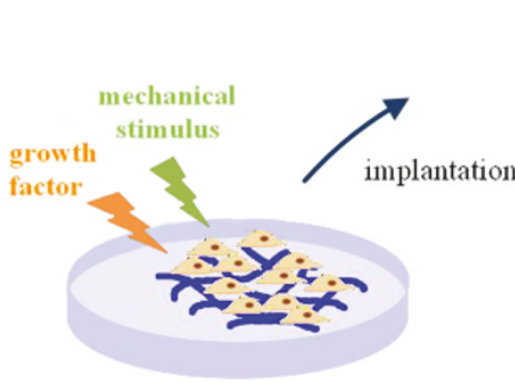

tissue development

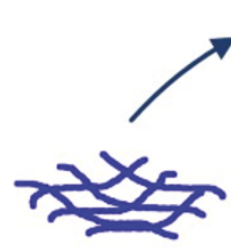

scaffold
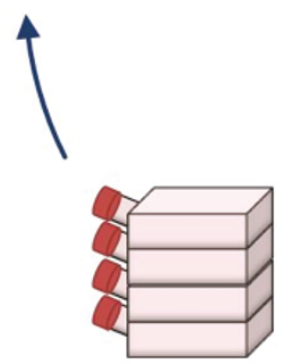

cell proliferation

巾

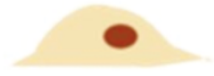

cell isolation

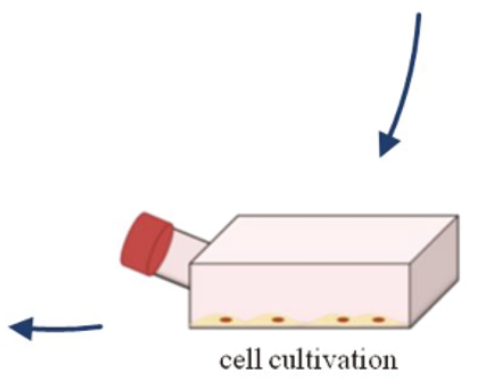

Figure 3. The tissue engineering paradigm. The tissue engineering paradigm consists of isolation and proliferation of a cell source, seeding of the cells onto a scaffold, stimulation of the cell-seeded scaffold to develop a tissue equivalent, and implantation of the construct in vivo. Figure reproduced under a Creative Commons Attribution 3.0 Unported license.

anabolic and catabolic factors during healing is what will likely drive the most successful repair to minimize scar formation and encourage the redevelopment of organized glenohumeral cartilage and tendon-to-bone insertion [78].

A targeted approach for enhanced repair using single growth factors embedded in scaffolds has been attempted in animal models in an effort to enhance rotator cuff [75] and cartilage repair [86]. Two recent studies demonstrated that TGF- $\beta 3$ may accelerate healing $[80,87]$. This growth factor has been implicated in fetal development and scarless fetal healing and, thus, addition of TGF- $\beta 3$ at the repaired tendon-to-bone insertion may enhance healing. Manning and colleagues [87] used a scaffold with controlled release of TGF- $\beta 3$ to encourage tendon-to-bone healing in a rat rotator cuff repair model. TGF- $\beta 3$ treatment led to increases in inflammation, cellularity, vascularity, and cell proliferation in the early period after surgical repair. The growth factor also promoted improvements in mechanical properties compared to controls. Cellular and gene transfer approaches have shown promise for improving rotator cuff repair as well. Gulotta and colleagues [88] delivered mesenchymal stem cells (MSCs) to the rotator cuff repair site in rats, but did not see improvements in healing. Positive results were only seen after MSCs were transfected with scleraxis $(\mathrm{Scx})$, a transcription factor that is necessary for tendon development [79]. Rotator cuff repairs that received Scx-transfected MSCs had higher strength and stiffness compared with the non-transfected MSC repairs. In a similar study, MSCs transfected with membrane type 1 matrix metalloproteinase (MT1-MMP), a factor that is upregulated during embryogenesis at tendon-bone insertion sites [84], showed significant improvements in healing compared to controls. Increased fibrocartilage production was noted at the repair site along with improvements in mechanical properties. Although both targeted growth factors and MSCs show great promise for enhancing rotator cuff repair, further safety and efficacy studies are needed to determine if results from animal studies can be applied effectively in the human surgical setting.

Recently, great interest has been given to biologic augmentation with platelet-rich-plasma (PRP). PRP is a solution of concentrated platelets prepared from autologous blood that contains numerous growth factors, including platelet-derived growth factor (PDGF), vascular endothelial growth factor (VEGF), and TGF- $\beta 1$ s [89]. Such factors make PRP an attractive option for the enhancement of recruitment, proliferation, and differentiation of cells in the repair site of soft tissue damage. The creation of higher-quality tissue at the repair site would likely enhance healing rates and clinical outcomes [90]. However, recent studies have demonstrated conflicting reports on the efficacy of exogenous supplementation of PRP for improving healing rates and improving clinical 
and functional outcomes [91,92]. In rotator cuff repair augmentation, Castricini and colleagues [91] recently investigated the use of PRP on patients with small or medium tears. In this study of patients with small $(<1 \mathrm{~cm})$ and medium $(1$ to $3 \mathrm{~cm})$ rotator cuff tears, augmentation with PRP at the time of rotator cuff repair did not improve Constant scores, tendon footprint thickness, or tendon thickness compared to repairs that were not augmented [91]. On the other hand, Randelli and colleagues [92] recently showed an accelerated improvement in clinical scores 3 months after surgery for patients treated with PRP at rotator cuff repair compared to those not treated with PRP. Patients treated with PRP also demonstrated reduced pain scores at 3, 7, 14, and 30 days post-operatively [92]. There was no difference in clinical scores or healing rates at longer-term follow up. Barber and colleagues [93] showed lower re-tear rates after rotator cuff repair with the use of platelet rich fibrin matrix, but interestingly, there was no difference in clinical outcome scores. Currently, use of PRP has marginal clinical support for treatment of rotator cuff repair or cartilage healing [89], and while PRP is a safe treatment for clinical use, its efficacy remains debatable.

\section{Conclusion}

Degenerative conditions of the shoulder remain a significant source of pain and disability in the general and aging populations. The burden of arthritis and rotator cuff disease makes them prime topics for basic and translational research. While total shoulder arthroplasty remains the last resort for treating severe glenohumeral disorders, such as OA, other therapies are emerging to aid in improving healing of native tissues. Tendon research has focused on preventing failures of rotator cuff repair and augmenting the biological healing of the rotator cuff. Many potential therapies hold promise, and the implementation of new technologies such as bioengineered scaffolds, novel stem cell sources, and controlled-release growth factors will likely navigate the future of treatment modalities for shoulder pathologies.

This article is part of the series on Cutting edge research and advances in orthopaedic research, edited by Edward Schwarz and Jay Lieberman. Other articles in this series can be found at http://arthritis-research.com/series/othopaedics

\section{Abbreviations}

MSC, mesenchymal stem cell; OA, osteoarthritis; PRP, platelet-rich plasma; TGF, transforming growth factor; TSA, total shoulder arthroplasty.

\section{Competing interests}

The authors do not have any competing interests related to the content of this review.

\section{Acknowledgements}

The authors received support from the National Institutes of Health (AR057836).
Published: 15 June 2012

\section{References}

1. Lawrence RC, Helmick CG, Arnett FC, Deyo RA, Felson DT, Giannini EH, Heyse SP, Hirsch R, Hochberg MC, Hunder GG, Liang MH, Pillemer SR, Steen VD, Wolfe F: Estimates of the prevalence of arthritis and selected musculoskeletal disorders in the United States. Arthritis Rheum 1998, 41:778-799.

2. Iannotti J, Williams G: Disorders of the Shoulder: Diagnosis and Management. Volume 1. Philadelphia: Lippincott Williams \& Wilkins; 2007.

3. Day J, Lau E, Ong K, Williams G, Ramsey M, Kurtz S: Prevalence and projections of total shoulder and elbow arthroplasty in the United States to 2015. J Shoulder Elbow Surg 2010, 19:1115-1120.

4. Yamamoto A, Takagishi K, Osawa T, Yanagawa T, Nakajima D, Shitara H, Kobayashi T: Prevalence and risk factors of a rotator cuff tear in the general population. J Shoulder Elbow Surg 2010, 19:116-120.

5. Moosmayer S, Smith H, Tariq R, Larmo A: Prevalence and characteristics of asymptomatic tears of the rotator cuff: an ultrasonographic and clinical study. J Bone Joint Surg Br 2009, 91:196-200.

6. Sher J, Uribe J, Posada A, Murphy B, Zlatkin M: Abnormal findings on magnetic resonance images of asymptomatic shoulders. J Bone Joint Surg Am 1995, 77:10-15.

7. Fuchs B, Weishaupt D, Zanetti M, Hodler J, Gerber C: Fatty degeneration of the muscles of the rotator cuff: assessment by computed tomography versus magnetic resonance imaging. J Shoulder Elbow Surg 1999, 8:599-605.

8. Gupta K, Duryea J, Weissman B: Radiographic evaluation of osteoarthritis. Radiol Clin North Am 2004, 42:11-41.

9. Millett PJ, Gobezie R, Boykin R: Shoulder osteoarthritis: diagnosis and management. Am Fam Physician 2008, 78:605-611.

10. Scalise J, Bryan J, Polster J, Brems J, lannotti J: Quantitative analysis of glenoid bone loss in osteoarthritis using three-dimensional computed tomography scans. J Shoulder Elbow Surg 2008, 17:328-335.

11. Ruckstuhl H, Bruin E, STussi E, Vanwanseele B: Post-traumatic glenohumeral cartilage lesions: A systematic review. BMC Musculoskelet Disord 2008, 8:1-8.

12. Zuckerman JD, Matsen FA 3rd: Complications about the glenohumeral joint related to the use of screws and staples. J Bone Joint Surg Am 1984, 66:175-180.

13. Chong PY, Srikumaran U, Kuye IO, Warner JJP: Glenohumeral arthritis in the young patient. J Shoulder Elbow Surg 2011, 20(2 Suppl):S30-S40.

14. Buchbinder R, Green S, Youd JM: Corticosteroid injections for shoulder pain. Cochrane Database Syst Rev 2003:CD004016.

15. Walch G, Boileau P, Noël E: Shoulder arthroplasty: evolving techniques and indications. Joint Bone Spine 2010, 77:501-505.

16. Orfaly RM, Rockwood CA Jr, Esenyel C, Wirth MA: Shoulder arthroplasty in cases with avascular necrosis of the humeral head. J Bone Joint Surg Am 2007, 16(3 Suppl):S27-S32.

17. Denard PJ, Wirth MA, Orfaly RM: Management of glenohumeral arthritis in the young adult. J Bone Joint Surg Am 2011, 93:885-892.

18. Cameron B, Galatz L, Ramsey M, Williams G, lannotti J: Non-prosthetic management of grade IV osteochondral lesions of the glenohumeral joint. J Shoulder Elbow Surg 2002, 11:25-32.

19. Van Thiel G, Sheehan S, Frank R, Slabaugh M, Cole B, Nicholson G, Romeo A, Verma N: Retrospective analysis of arthroscopic management of glenohumeral degenerative disease. Arthroscopy 2010, 26:1451-1455.

20. Torchia ME, Cofield RH, Settergren CR: Total shoulder arthroplasty with the Neer prosthesis: long-term results. J Shoulder Elbow Surg 1997, 6:495-505.

21. Wirth M: Humeral head arthroplasty and meniscal allograft resurfacing of the glenoid. J Bone Joint Surg Am 2009, 91:1 109-1119.

22. Burkhead W Jr, Krishnan S, Lin K: Biologic resurfacing of the arthritic glenohumeral joint: Historical review and current applications. J Shoulder Elbow Surg 2007, 16:S248-253.

23. Krishnan S, Nowinski R, Harrison D, Burkhead W: Humeral hemiarthroplasty with biologic resurfacing of the glenoid for glenohumeral arthritis. Two to fifteen-year outcomes. J Bone Joint Surg Am 2007, 89:727-734.

24. Hattrup SJ, Cofield RH: Osteonecrosis of the humeral head: results of replacement. J Shoulder Elbow Surg 2000, 9:177-182.

25. Levy O, Copeland SA: Cementless surface replacement arthroplasty (Copeland CSRA) for osteoarthritis of the shoulder. J Shoulder Elbow Surg 2004, 13:266-271.

26. Thomas SR, Sforza G, Levy O, Copeland SA: Geometrical analysis of Copeland surface replacement shoulder arthroplasty in relation to normal 
anatomy. J Shoulder Elbow Surg 2005, 14:186-192.

27. Izquierdo R, Voloshin I, Edwards S, Freehill MQ, Stanwood W, Wiater JM, Watters WC 3rd, Goldberg MJ, Keith M, Turkelson CM, Wies JL, Anderson S, Boyer K, Raymond L, Sluka P; American Academy of Orthopedic Surgeons: Treatment of glenohumeral osteoarthritis. J Am Acad Orthop Surg 2010, 18:375-382.

28. Wiater J, Fabing M: Shoulder arthroplasty: prosthetic options and indications. J Am Acad Orthop Surg 2009, 17:415-425.

29. Bohsali KI, Wirth MA, Rockwood CA Jr: Complications of total shoulder arthroplasty. J Bone Joint Surg Am 2006, 88:2279-2292.

30. Gonzalez J-F, Alami GB, Baque F, Walch G, Boileau P: Complications of unconstrained shoulder prostheses. J Shoulder Elbow Surg 2011, 20:666-682.

31. Litchfield R, McKee MD, Balyn R, Mandel S, Holtby R, Hollinshead R, Drosdowech D, Wambolt S, Griffin S, McCormack R: Cemented versus uncemented fixation of humeral components in total shoulder arthroplasty for osteoarthritis of the shoulder: a prospective, randomized, double-blind clinical trial-A JOINTs Canada Project. J Shoulder Elbow Surg 2011, 20:529-536.

32. Wirth MA, Klotz C, Deffenbaugh DL, McNulty D, Richards L, Tipper JL: Crosslinked glenoid prosthesis: a wear comparison to conventional glenoid prosthesis with wear particulate analysis. J Shoulder Elbow Surg 2009, 18:130-137.

33. Lynch JR, Franta AK, Montgomery WH Jr, Lenters TR, Mounce D, Matsen FA 3rd: Self-assessed outcome at two to four years after shoulder hemiarthroplasty with concentric glenoid reaming. J Bone Joint Surg Am 2007, 89:1284-1292.

34. Bryant D, Litchfield R, Sandow M, Gartsman GM, Guyatt G, Kirkley A A comparison of pain, strength, range of motion, and functional outcomes after hemiarthroplasty and total shoulder arthroplasty in patients with osteoarthritis of the shoulder. A systematic review and meta-analysis. J Bone Joint Surg Am 2005, 87:1947-1956.

35. Edwards TB, Kadakia NR, Boulahia A, Kempf JF, Boileau P, Nemoz C, Walch G: A comparison of hemiarthroplasty and total shoulder arthroplasty in the treatment of primary glenohumeral osteoarthritis: results of a multicenter study. J Shoulder Elbow Surg 2003, 12:207-213.

36. Singh JA, Sperling J, Buchbinder R, McMaken K: Surgery for shoulder osteoarthritis. Cochrane Database Syst Rev 2010:CD008089.

37. Matsen FA 3rd, Clark JM, Titelman RM, Gibbs KM, Boorman RS, Deffenbaugh D, Korvick DL, Norman AG, Ott SM, Parsons IM 4th, Sidles JA: Healing of reamed glenoid bone articulating with a metal humeral hemiarthroplasty: a canine model. J Orthop Res 2005, 23:18-26.

38. Ecklund KJ, Lee TQ, Tibone J, Gupta R: Rotator cuff tear arthropathy. J Am Acad Orthop Surg 2007, 15:340-349.

39. Mulieri P, Dunning P, Klein S, Pupello D, Frankle M: Reverse shoulder arthroplasty for the treatment of irreparable rotator cuff tear without glenohumeral arthritis. J Bone Joint Surg Am 2010, 92:2544-2556.

40. Galatz LM, Ball CM, Teefey SA, Middleton WD, Yamaguchi K: The outcome and repair integrity of completely arthroscopically repaired large and massive rotator cuff tears. J Bone Joint Surg Am 2004, 86-A:219-224.

41. Boileau P, Brassart N, Watkinson D, Carles M, Hatzidakis A, Krishnan S: Arthroscopic repair of full-thickness tears of the supraspinatus: does the tendon really heal? J Bone Joint Surg Am 2005, 87:1229-1240.

42. Tashijian RZ, Hollins AM, Kim HM, Teefey SA, Middleton WD, Steger-May K, Galatz LM, Yamaguchi K: Factors affecting healing rates after arthroscopic double-row rotator cuff repair. Am J Sports Med 2010, 38:2435-2442.

43. Ward SR, Sarver JJ, Eng CM, Kwan A, Worgler-Hauri CC, Perry SM, Williams GR, Soslowsky $\sqcup$, Lieber RL: Plasticity of muscle architecture after supraspinatus tears. J Orthop Sports Phys Ther 2010, 40:729-735.

44. Shimizu T, Itoi E, Minagawa H, Pradhan RL, Wakabayashi I, Sato K: Atrophy of the rotator cuff muscles and site of cuff tears. Acta Orthop Scand 2002, 73:40-43

45. Gerber C, Meyer DC, Schneeberger AG, Hoppeler H, von Rechenberg B: Effect of tendon release and delayed repair on the structure of the muscles of the rotator cuff: an experimental study in sheep. J Bone Joint Surg Am 2004, 86-A:1973-1982

46. Galatz LM, Charlton N, Das R, Kim HM, Havlioglu N, Thomopoulos S: Complete removal of load is detrimental to rotator cuff healing. J Shoulder Elbow Surg 2009, 18:669-675.

47. Kim HM, Dahiya N, Teefey SA, Keener JD, Galatz LM, Yamaguchi K: Relationship of tear size and location to fatty degeneration of the rotator cuff. J Bone Joint Surg Am 2010, 92:829-839.
48. Gimbel JA, Van Kleunen JP, Lake SP, Williams GR, Soslowsky LJ: The role of repair tension on tendon to bone healing in an animal model of chronic rotator cuff tears. J Biomech 2006, 40:561-568.

49. Safran O, Derwin KA, Powell K, lannotti JP: Changes in rotator cuff muscle volume, fat content, and passive mechanics after chronic detachment in a canine model. J Bone Joint Surg Am 2005, 87:2662-2670.

50. Kim HM, Galatz LM, Lim C, Havlioglu N, Thomopoulos S: The eff ect of tear size and nerve injury on rotator cuff muscle fatty degeneration in a rodent animal model. J Shoulder Elbow Surg Am 2011 [Epub ahead of print].

51. Rowshan K, Hadley S, Pham K, Caiozzo V, Lee TQ, Gupta R: Development of fatty atrophy after neurologic and rotator cuff injuries in an animal model of rotator cuff pathology. J Bone Joint Surg Am 2010, 92:2270-2278.

52. Thomopoulos S, Williams GR, Soslowsky LJ: Tendon to bone healing: differences in biomechanical, structural, and compositional properties due to a range of activity levels. J Biomech Eng 2003, 125:106-113.

53. Harryman DT, 2nd, Mack LA, Wang KY, Jackins SE, Richardson ML, Matsen FA 3rd: Repairs of the rotator cuff. Correlation of functional results with integrity of the cuff. J Bone Joint Surg Am 1991, 73:982-989.

54. Koh KH, Kang KC, Lim TK, Shon MS, Yoo JC: Prospective randomized clinical trial of single- versus double-row suture anchor repair in 2- to 4-cm rotator cuff tears: clinical and magnetic resonance imaging results. Arthroscopy 2011, 27:453-462.

55. Ma H-L, Chiang E-R, Wu H-TH, Hung S-C, Wang S-T, Liu C-L, Chen T-H: Clinical outcome and imaging of arthroscopic single-row and double-row rotator cuff repair: a prospective randomized trial. Arthroscopy 2012, 28:16-24.

56. Charousset C, Bellaïche L, Kalra K, Petrover D: Arthroscopic repair of fullthickness rotator cuff tears: is there tendon healing in patients aged 65 years or older? Arthroscopy 2010, 26:302-309.

57. Dodson CC, Dodson CC, Kitay A, Verma NN, Adler RS, Nquyen J, Cordasco FA, Altchek DW: The long-term outcome of recurrent defects after rotator cuff repair. Am J Sports Med 2010, 38:35-39.

58. Duquin TR, Buyea C, Bisson LJ: Which method of rotator cuff repair leads to the highest rate of structural healing? A systematic review. Am J Sports Med 2010, 38:835-841.

59. Jost B, Zumstein M, Pfirrmann CWA, Gerber C: Long-term outcome after structural failure of rotator cuff repairs. J Bone Joint Surg Am 2006, 88:472-479.

60. Galatz LM, Sandell LJ, Rothermich SY, Das R, Mastny A, Havlioglu N, Silva MJ, Thomopoulos S: Characteristics of the rat supraspinatus tendon during tendon-to-bone healing after acute injury. J Orthop Res 2006, 24:541-550.

61. Thomazeau H, Boukobza E, Morcet N, Chaperon J, Langlais F: Prediction of rotator cuff repair results by magnetic resonance imaging. Clin Orthop Related Res 1997, 344:275-283

62. Miller BS, Downie BK, Kohen RB, KijekT, Lesniak B, Jacobson JA, Hughes RE, Carpenter JE: When do rotator cuff repairs fail? Serial ultrasound examination after arthroscopic repair of large and massive rotator cuff tears. Am J Sports Med 2011, 39:2064-2070.

63. Trappey G, Gartsman G: A systematic review of the clinical outcomes of single row versus double row rotator cuff repairs. J Shoulder Elbow Surg 2011, 20(2 Suppl):S14-19

64. Pennington WT, Gibbons DJ, Bartz BA, Dodd M, Daun J, Klinger J, Popovich M, Butler B: Comparative analysis of single-row versus double-row repair of rotator cuff tears. Arthroscopy 2010, 26:1419-1426.

65. Savoie FH, 3rd, Brislin KJ, Argo D: Arthroscopic glenoid resurfacing as a surgical treatment for glenohumeral arthritis in the young patient: midterm results. Arthroscopy 2009, 25:864-871.

66. Gobezie R, Lenarz CJ, Wanner JP, Streit J): All-arthroscopic biologic total shoulder resurfacing. Arthroscopy 2011, 27:1588-1593.

67. Gerber C, Lambert SM: Allograft reconstruction of segmental defects of the humeral head for the treatment of chronic locked posterior dislocation of the shoulder. J Bone Joint Surg Am 1996, 78:376-382.

68. Johnson DL, Warner JJ: Osteochondritis dissecans of the humeral head: treatment with a matched osteochondral allograft. J Shoulder Elbow Surg 1997, 6:160-163.

69. Romeo AA, Cole BJ, Mazzocca AD, Fox JA, Freeman KB, Joy E: Autologous chondrocyte repair of an articular defect in the humeral head. Arthroscopy 2002, 18:925-929.

70. Derwin KA, Badylak SF, Steinmann SP, lannotti JP: Extracellular matrix scaffold devices for rotator cuff repair. J Shoulder Elbow Surg 2010, 19:467-476.

71. Wang IN, Shan J, Choi R, Oh S, Kepler CK, Chen FH, Lu HH: Role of 
osteoblast-fibroblast interactions in the formation of the ligament-tobone interface. J Orthop Res 2007, 25:1609-1620.

72. Spalazzi JP, Doty SB, Moffat KL, Levine WN, Lu HH: Development of controlled matrix heterogeneity on a triphasic scaffold for orthopedic interface tissue engineering. Tissue Eng 2006, 12:3497-3508.

73. Li X, X ie J, Lipner J, Yuan X, Thomopoulos S, Xia Y: Nanofiber scaffolds with gradations in mineral content for mimicking the tendon-to-bone insertion site. Nano Lett 2009, 9:2763-2768.

74. Phillips JE, Burns KL, Le Doux JM, Guldberg RE, Garcia AJ: Engineering graded tissue interfaces. Proc Natl Acad Sci U S A 2008, 105:12170-12175.

75. Montgomery S, Petrigliano FA, Gamradt S: Biological augmentation of rotator cuff repair. Curr Rev Musculoskel Med 2011, 4:221-230.

76. Thomopoulos S, Das R, Birman V, Smith L, Ku K, Elson E, Pryse KM, Marquez P, Genin GM: Fibrocartilage tissue engineering: the role of the stress environment on cell morphology and matrix expression. Tissue Eng Part A 2011, 17:1039-1053.

77. Garofalo R, Cesari E, Vinci E, Castagna A: Role of metalloproteinases in rotator cuff tear. Sports Med Arthrosc 2011, 19:207-212.

78. Gulotta LV, Rodeo SA: Growth factors for rotator cuff repair. Clin Sports Med 2009, 28:13-23.

79. Gulotta LV, Kovacevic D, Packer JD, Deng XH, Rodeo SA: Bone marrowderived mesenchymal stem cells transduced with scleraxis improve rotator cuff healing in a rat model. Am J Sports Med 2011, 39:1282-1289.

80. Kovacevic D, Fox AJ, Bedi A, Ying L, Deng XH, Warren RF, Rodeo SA: Calciumphosphate matrix with or without TGF-beta 3 improves tendon-bone healing after rotator cuff repair. Am J Sports Med 2011, 39:811-819.

81. Gulotta LV, Kovacevic D, Packer JD, Ehteshami JR, Rodeo SA: Adenoviralmediated gene transfer of human bone morphogenetic protein-13 does not improve rotator cuff healing in a rat model. Am J Sports Med 2011, 39:180-187.

82. Rodeo SA: Biologic augmentation of rotator cuff tendon repair. J Shoulder Elbow Surg 2007, 16(5 Suppl):S191-197.

83. Rodeo SA, Potter HG, Kawamura S, Turner AS, Kim HJ, Atkinson BL: Biologic augmentation of rotator cuff tendon-healing with use of a mixture of osteoinductive growth factors. J Bone Joint Surg Am 2007, 89:2485-2497.

84. Gulotta LV, Kovacevic D, Montgomery S, Ehteshami JR, Packer JD, Rodeo SA: Stem cells genetically modified with the developmental gene MT1-MMP improve regeneration of the supraspinatus tendon-to-bone insertion site. Am J Sports Med 2010, 38:1429-1437.

85. Rodeo SA, Suzuki K, Deng XH, Wozney J, Warren RF: Use of recombinant human bone morphogenetic protein- 2 to enhance tendon healing in a bone tunnel. Am J Sports Med 1999, 27:476-488.

86. Maher S, Mauck RL, Rackwitz L, Tuan RS: A nanofibrous cell-seeded hydrogel promotes integration in a cartilage gap model. J Tissue Eng Regen Med 2010, 4:25-29.
87. Manning CN, Kim HM, Sakiyama-Elbert S, Galatz LM, Havlioglu N, Thomopoulos S: Sustained delivery of transforming growth factor beta three enhances tendon-to-bone healing in a rat model. J Orthop Res 2011, 29:1099-1105.

88. Gulotta LV, Kovacevic D, Ehteshami JR, Dagher E, Packer JD, Rodeo SA: Application of bone marrow-derived mesenchymal stem cells in a rotator cuff repair model. Am J Sports Med 2009, 37:2126-2133.

89. Hall MP, Band PA, Meislin RJ, Jazrawi LM, Cardone DA: Platelet-rich plasma: current concepts and application in sports medicine. J Am Acad Orthop Surg 2009, 17:602-608.

90. Lopez-Vidriero E, Goulding KA, Simon DA, Sanchez M, Johnson DH: The use of platelet-rich plasma in arthroscopy and sports medicine: optimizing the healing environment. Arthroscopy 2010, 26:269-278.

91. Castricini R, Longo UG, De Benedetto M, Panfoli N, Pirani P, Zini R, Maffulli N, Denaro V: Platelet-rich plasma augmentation for arthroscopic rotator cuff repair: a randomized controlled trial. Am J Sports Med 2011, 39:258-265.

92. Randelli P, Arrigoni P, Ragone V, Aliprandi A, Cabitza P: Platelet rich plasma in arthroscopic rotator cuff repair: a prospective RCT study, 2-year follow-up. J Shoulder Elbow Surg 2011, 20:518-528.

93. Barber FA, Hrnack SA, Snyder SJ, Hapa O: Rotator cuff repair healing influenced by platelet-rich plasma construct augmentation. Arthroscopy 2011, 27:1029-1035.

94. Elhassan B, Ozbaydar M, Diller D, Higgins LD, Warner JJ: Soft-tissue resurfacing of the glenoid in the treatment of glenohumeral arthritis in active patients less than fifty years old. J Bone Joint Surg Am 2009, 91:419-424

95. Chahal J, Mall N, Macdonald P, Van Thiel G, Cole B, Romeo A, Verma N: The role of subacromial decompression in patients undergoing arthroscopic repair of full-thickness tears of the rotator cuff: a systematic review and meta-analysis. Arthroscopy 2012, 28:720-727.

96. Henkus H, de Witte P, Nelissen R, Brand R, van Arkel E: Bursectomy compared with acromioplasty in the management of subacromial impingement syndrome: a prospective randomised study. J Bone Joint Surg Br 2009. 91:504-510.

97. Neri B, Chan K, Kwon Y: Management of massive and irreparable rotator cuff tears. J Shoulder Elbow Surg 2009, 18:808-818.

doi:10.1186/ar3846

Cite this article as: Killian ML, et al.: Recent advances in shoulder research. Arthritis Research \& Therapy 2012, 14:214. 